Article

\title{
An Approach to Increase the Sustainability of Projects and their Outcomes in Public Sector through Improving Project Definition
}

\author{
Dorota Kuchta * (D) and Jagoda Mrzygłocka-Chojnacka *(D) \\ Faculty of Computer Science and Management, Wrocław University of Science and Technology, Wyb. \\ Wyspianskiego 27, 50-370 Wrocław, Poland \\ * Correspondence: dorota.kuchta@pwr.edu.pl (D.K.); jagoda.mrzyglocka-chojnacka@pwr.edu.pl (J.M.-C.)
}

Received: 22 April 2020; Accepted: 10 June 2020; Published: 12 June 2020

\begin{abstract}
The pressure to incorporate sustainability principles and objectives into policies and activities is growing, particularly in project management. A successful project cannot disregard any of the three triple bottom line (TBL) sustainability pillars (economic, social and environmental). Stakeholders representing each of those pillars have to be satisfied to a certain degree in each successful project, even if the way of balancing the three pillars varies depending on project type. Project definition is of primary importance for the proper addressing of stakeholder expectations during the project, and thus for project success. The problem is that project definitions in practice are not written in a way which would guarantee a sufficient degree of project sustainability. However, the hypothesis can be formulated that a systematic analysis and modification of project definition can increase the degree of project sustainability, and thus the degree of project success. That is why we propose here a method of checking and improving existing project definitions in order to improve the chances of project success through increasing the satisfaction of the stakeholders representing the three TBL pillars. The method is based on a careful identification of missing and ambiguous information in a project definition and on correcting it on the basis of TBL stakeholders' opinions and preferences. These preferences are modelled, wherever possible, by means of fuzzy sets, in order to provide a systematic, formal measurement of sustainability degree in TBL sustainability pillars, represented by project stakeholders. The method's use and potential advantages are illustrated by means of two real world projects. The initial verification of the method allows us to formulate the hypothesis that analysing and improving project definition may considerably contribute to increasing the sustainability degree of projects, and thus to their success.
\end{abstract}

Keywords: project scope; project objectives; project requirements; sustainability; project success

\section{Introduction}

There exist many definitions of sustainability, but it is generally assumed that sustainability stands for balancing economic, social and environmental objectives and the impact of human activity [1]. As underlined in [2,3], the principles of sustainability should dominate every context of business and organizational management. The project management area is no exception. Even if projects have become increasingly globalized, they also pose challenges to local communities and governments, with sustainable development being one of these challenges. Projects consume resources and produce specific deliverables, and both have economic, social and environmental impacts, often reaching far beyond project official closure.

In the authors' opinion, sustainability is linked to any human action on its environment. All these actions, through projects or otherwise, must not be governed merely by economic motivations. For this 
reason, in recent years, sustainability has been becoming an important issue in project management research [1,2,4-21]. One of the most important conclusions of this research is that in today's projects, there is a clear link between sustainability and project success [13,22-27]. Whatever the adopted definition of project success is, in numerous cases, this success cannot be attained to a sufficient degree without taking sustainability into account. Sustainability means, among other things, that a project cannot be considered to be a success if the key project stakeholders are not satisfied with project outcomes and impact to a sufficient degree [28]. Accepting sustainability as a principle which should be present in each human action, we have to conclude that in order for a project to be successful, we have to satisfy stakeholders representing the three triple bottom line (TBL) pillars [29]. Of course, the required balance of satisfaction between the different stakeholders will be different depending on the project (the weight of, for example, "environmental" stakeholders will be usually smaller in IT than in construction projects [30]), but all the stakeholder groups, representing all TBL pillars, have to be taken into account to a certain degree if a project is to be successful [29].

The existing project management methodologies do not explicitly cover sustainability $[2,12,31,32]$. They comprise various areas involving sustainability, such project stakeholders management [31], and sometimes the sustainability is even explicitly mentioned (e.g., in the Agile Manifesto [33]), but sustainability in the sense of requiring a certain balance between the three TBL pillars is absent. Among others, it is absent from the project defining or initiating process [31]. In the literature, it is underlined that the process of project definition is of primary importance for project success [1,34]. It is in this stage that it is determined what is going to be done in the project, in relation to the expectations of the customers. It is also in this stage that project stakeholders should be identified and analysed with respect to their expectations and attitudes. Thus, if in the stage of project definition the satisfaction of project stakeholders is not correctly identified and described, it is highly probable that the final outcome of the project may not satisfy them sufficiently and the project will not be successful. It is thus essential to define the expected project minimal sustainability degree, defined as the satisfaction of the stakeholders in the three TBL pillars, in the project definition stage. This is in line with the literature findings: the authors of [1] and [35] underlined that it is of highest importance to consider sustainability (in the sense of the TBL pillars) during the front-end of projects. In [36], we can read that it is irrational to ask stakeholders' opinions in later project stages, without having asked it in the project definition phase.

In the literature, the authors of the present paper have not identified any research which would refer to taking sustainability into account in the process of project defining. Our aim is to partially cover this gap, although we do not intend to propose a general procedure of project defining with sustainability considerations, as in the present stage of research, this aim seems to us too ambitious and should be seen rather as a long term objective. Our aim is to propose a method of improving existing project definitions in order to increase the sustainability degree of the project in question, measured by the satisfaction of project stakeholders representing each of the three sustainability pillars: economic, social and environmental. The improved process should be executed through a careful analysis (and subsequently the correction or insertion of a formal description of the desired satisfaction degree) of the formulations used in the project definition, performed by the three stakeholder groups. The hypothesis is that a systematic reading, correcting and completing of an existing project definition will increase the sustainability degree of the project, and thus its success probability. The choice of this research objective and hypothesis has the following motivation:

- The practical observations of the authors of the present paper (made in the position of project reviewers and auditors, as well as research fund applicants) show that real life project definitions contain numerous ambiguous and unclear formulations, which is also supported by the literature [37,38]. This phenomenon may have various reasons. Sometimes the ambiguities are purposeful: not all the information is available yet or certain decisions have not been taken yet. Sometimes the lack of clarity is a consequence of the fact that project definitions are often 
compiled by various scattered groups, in a hurry or in the last moment before a deadline in calls for projects, and are focused on winning a specific project call;

- the few existing research papers (not related to sustainability) on project definition clearly showed that it is possible and necessary to improve existing project definitions with the objective of increasing the project success possibility. Papers $[37,38]$ examined the question of improving project definitions in order to increase project success probability through the identification and analysis of ambiguities in project definition. In [37], those ambiguities were modeled by means of fuzzy sets;

- no papers referring to the above problem of project definition correction have been identified which would refer to sustainability.

According to the objective formulated above, we propose a method of improving project definition in order to increase the possibility degree of project success in terms of sustainability, understood as the balanced satisfaction of stakeholders representing the TBL pillars. The justification and the usage of the method is illustrated and analysed by means of the case study approach. A real-world project is used here. This project was terminated with a formal, but unfortunately not actual success. This case study shows the high potential usefulness of the method and delivers an initial positive verification of the hypothesis that a thorough analysis of project definition can substantially increase the sustainability degree of projects and thus the possibility of their success. Apart from the case study, the method is submitted to two other initial validation endeavours.

The research methodology is as follows: first, we use the grounded theory approach [39], thanks to which we propose- on the basis of literature proposals referring to improving project definition outside the sustainability context-a method (in the form of an algorithm) of improving project definition in order to increase the possibility degree of project success in terms of sustainability. Then we verify this method using the case study approach [40] (two case studies are used) and a fresh concept validation method [41].

The outline of the paper is as follows: in Section 2 (Literature review), we present the literature review on topics related to the objective of the paper: project success, project definition, project stakeholders, sustainability with respect to projects and the importance of project definition for project success. In Section 3 (Materials and methods), we describe our research methodology, present the essential element of the paper-the proposed method of analysing and modifying project definition-and introduce the real world project which is used as a case study in the verification of our method. In Section 4 (Results), we analyse the results of the application of our method to the case study project and to another real world project, and we present the results of the initial validation of the method. The paper terminates with some conclusions.

\section{Literature Review}

This section's structure results from the objective of the present paper: to propose a new approach of analysing the wording of project definition in order to improve the sustainability degree of the project and ultimately to increase its success probability. This approach will consist of a careful identification of missing and ambiguous information in project definition and in correcting it on the basis of various stakeholders' opinions and preferences, while these preferences will be modelled by means of fuzzy sets. Thus, first the notion of project and project definition will be defined and then basic theory referring to project stakeholders will be presented. Subsequently, the relationship between project success, project stakeholders and the sustainability in and of the project will be analysed. Finally, the literature justifying the fact that project definition is of utmost importance for project success will be summarized and the existing approaches (not connected to sustainability) for analysing the wording of project definition in order to increase project success probability will be presented. The literature review section will terminate with basic information regarding fuzzy sets. 


\subsection{Project Definition}

A project can be described as a temporary endeavour undertaken to create a unique product, service, or result [42]. Projects have specific lifecycles. Once the idea of a project has been initially accepted and before the project passes to the actual planning and realization, it has to be defined. Project definition takes on various forms and names (like a statement of work, project charter or project chart), but it always encompasses [43], among others, the presentation of project objectives, the description of the main deliverables (thus, expected outcomes) of the project and the technical requirements for the expected project outcomes and their expected performance.

Another important element of project definition is the description of main tasks (activities) to be performed in the project [43]. They are identified through a progressive breakdown of project scope in the work breakdown structure.

Another element of project definition is the project communication plan [43], whose elaboration should be preceded by project stakeholder identification and analysis. The problem of project stakeholders will be examined in the next section.

\subsection{Project Stakeholders}

A very important notion-from the point of view of project management and the theme of this paper-is project stakeholder management. Srinivasan and Dhivya [44] and Krane et al. [45] defined project stakeholder as a person or a group of persons who are influenced by, or able to influence, the project, regardless of whether they have on official role in the project or not. Generally, stakeholders can be of two categories: internal and external ones. Internal stakeholders are directly involved in the decision-making process of the organisation in which the project is located (e.g., customers, owners, suppliers, employees), and external stakeholders are other persons or groups of persons who are affected by the project's activities (e.g., general public, local community, local authorities) [15].

Project stakeholders should be identified before the project's start and analysed with respect to their role, attitude towards the project, influence possibilities and willingness etc., and afterwards contacted and managed, respectively [44-46]. Stakeholders in various categories have to be described and given weights: the most important stakeholders from the point of view of a given aspect should have most to say regarding this aspect. For example, as far as the economic aspect of a project is concerned, the most important stakeholders (with the highest weights) would be those who may influnce or be influenced by decisions regarding financial resources, such as sponsors, financial managers etc.

\subsection{Project Success in Relation to Project Stakeholders and Sustainability}

Project success can be and is defined in the literature in many different ways. A recent summary of the research on project success can be found in [47]. Apart from the classical so-called Iron Triangle Model, according to which a successful project is one which is completed on time, within budget and which covers the whole planned scope with due quality, today the understanding of project success is much more comprehensive. Project success is more and more often related to the benefits as a whole that are provided by the project [48]. In [47], we can find various dimensions of project success, including preparation for the future, which emphasizes the need for a longer horizon for project success determination, the impact on customers and the impact on the team, and generally on project key stakeholders [49]. However, in more and more projects today, key project stakeholders are linked to all the three TBL pillars of sustainability (triple bottom line-economic, environmental and social) [7], which means that in numerous cases, project success cannot be achieved without taking into account sustainability in all its dimensions.

Reviews of all the scientific literature referring to sustainability in project management can be found in [50] and [2]. In [29] (p. 79), we can find the following definition of sustainable project management: "Sustainable Project Management is the planning, monitoring and controlling of project delivery and support processes, with consideration of the environmental, economic and social aspects of 
the life cycle of the project's resources, processes, deliverables and effects, aimed at realizing benefits for stakeholders, and performed in a transparent, fair, and ethical way that includes proactive stakeholder participation." This definition underlines on one hand the sustainability in projects, thus during their realization, in the "project delivery and support processes", which includes project definition, but on the other hand, it makes a clear reference to project success, defined as realizing benefits for stakeholders. It also draws our attention to the importance of stakeholders' proactive participation. The primary role of stakeholders in each stage of the project, or even in its whole life cycle [10], has to be understood and taken into account by each project manager (although we have to bear in mind that project strategy cannot focus solely on generating stakeholder value [51]). Another issue of utmost importance is the sustainability of the project, or of the project product. As stakeholder expectations go far beyond the project closure point, project products are expected to be sustainable [52], and in order to meet this expectation, involvement of the stakeholders in project definition (which encompasses project product definition) is absolutely necessary. A close relationship between project stakehholders and sustainability was also emphasized in [53] and in numerous papers referring to case studies or special project types [54-61].

\subsection{Importance of Project Definition for the Probability of Attaining Project Success}

Gibson et al. [62] noted that the purpose of project definition is to provide adequate information that is needed to identify the work to be performed in order to avoid major changes that may negatively affect project performance. A poor project definition can lead to expensive changes, delays, reworks, cost overruns, schedule overruns, and even project failure [36]. Asadabadi et al. [37] indicated that the process of requirement specification is extremely important and if it is not performed properly, it can later give rise to serious conflicts and disagreements. Atkinson, Crawford and Ward [63] noted that when a project proceeds to the implementation stages with inadequate definition, it may be subjected to different expectations and interpretations by different stakeholders. These statements point to the fact that neglecting the phase of project definition can result in stakeholder dissatisfaction. In the context of sustainability, it is important to underline that it is the initiation and planning stages of projects that provide opportunities for integrating the concept of sustainability into the project [51].

\subsection{Existing Approaches to Improving Project Definition for the Sake of Increasing the Probability of Project Success}

Almost all identified articles devoted to the analysis of project definition for the sake of increasing project success probability, except for [37], concerned IT or construction projects, and dealt with such issues linked with imperfect project definitions as a lack of traceability [64], incompleteness [65], and internal conflicts [66]. Several authors proposed methods of text analysis, identifying all ambiguities in project definitions, including certain grammar forms which may lead to ambiguities (like the passive voice) - [38,67-70]). In [38] and [69], the authors called ambiguous formulations in project definition "smells". They argued that "smells" should be identified and made precise before the project is actually started. The authors of the papers cited above provided some methods of automated text analysis whose aim is the identification of the "smells", and some authors (e.g., [70]) provided proposals on how to make up for the ambiguity. Other authors attempted to define the notion of requirements quality. In [71], we can read about syntactic (correctness), semantic (validity and completeness), pragmatic (understandability) and social (agreement between stakeholders) requirements quality. For checking requirements' completeness, the construction industry has developed a tool called the Project Definition Rating Index (PDRI) [72]. In [73], relationships between IT requirements were classified into four groups: conflicting, cooperative, mutually exclusive and irrelevant. The mere names of the categories suggest project definition lacking quality and the need for an improvement.

Although the aim of research on project definition is often to remove the ambiguity, some authors recognised that this ambiguity is in many cases unavoidable in the preparatory project stage, and concentrated on elaborating methods of making these unavoidable ambiguities explicit and 
measurable. In [37], the authors defined, referring to projects (not necessarily IT projects) definition, so called "Hidden Fuzzy Terms", by which they meant information that is implied and includes ambigous, or-as the authors described it-fuzzy words. They referred to the situation when the person writing the project definition assumes that the reader will know what he or she means and therefore skips explaining specifically, or does not state explicitly some hidden information. But if the skipped information is per se imprecise, or fuzzy, the reader's impresion may later turn out to be incoherent with the writer's assumption. The authors of [37] proposed an algorithm of identifying hidden fuzzy terms, modelling them by means of fuzzy numbers and measuring the satisfaction of the reader (usually, the customer, but this may also apply to other project stakeholders) with an arbitrary final solution, where all fuzzy numbers finally have to become crisp.

In [37], the authors dealt with two (possibly collective) stakeholders: the writer of the project definition and the customer. However, other authors [36] drew attention to the fact that each project has several stakeholders, and that a good project definition cannot be worked out without involving all stakeholders in defining the project. These authors noted that it is irrational to get stakeholders' opinions about the project outcome only after the project completion. Therefore, when the input of one or more key stakeholders is intentionally or unintentionally omitted in the project defining stage, incomplete project definition may occur and this may have serious consequences for project success. In addition, the psychological aspect cannot be forgotten: the mere fact of participating in the process of defining the project increases the satisfaction with project outcome, even if objectively this outcome may seem not so satisfactory [36].

Among the existing approaches to improving project definition for the sake of increasing the probability of project success, we have not identifed any which would:

- take various groups of stakeholders into account, with the objective to balance their often conflicting interests and expectations;

- refer to projects from other areas than IT and construction;

- take sustainability into account.

It has to underlined that known project management methodologies, such as PMI or PRINCE and Agile, do not comprise any method of correcting an existing project definition. That is why we formulated the following objective of our research: to propose a method of improving existing project definitions in order to increase the sustainability degree of the project in question, measured by the satisfaction of project stakeholders, representing each of the three sustainability pillars: economic, social and environmental. This method will be proposed in Section 3.2.

\section{Materials and Methods}

\subsection{Research Methodology}

The basic framework followed for the purpose of elaborating a new approach of analysing the wording of the project definition in order to improve project's sustainability degree is shown in Figure 1.

\begin{tabular}{|c|}
\hline Step 2: Grounded Theory - elaboration of the method of improving project definition from the point of view of sustainability \\
\hline Step 3: qualitative research - verification of the method: the case study approach \\
\hline Step 4: additional validation and verification of the proposed method \\
\hline
\end{tabular}

Figure 1. Research methodology. 
Step 1. Literature review-apart from some classic literature from where certain notions used in our paper were taken, the latest literature from the Scopus database was analysed, in order to:

(a) prove that sustainability is today a conditio sine qua non of project success (here we searched for papers with key words "sustainability" and "project" and "success" in the title);

(b) prove that the phase of project definition is primordial for project success (here we searched for papers with key words ("definition" or "specification" or "scope" or "chart") and "project" and "success" in the title);

(c) identify all the papers referring to the problem of analysing and modifying existing project definitions, with the participation of project stakeholders, in order to increase the success possibility of the project; here we searched for papers with key words ("definition" or "specification" or "scope" or "chart") and "project" and in the title).

The results of the literature review are presented in Section 2. It has to be underlined that no papers have been identified which dealt with correcting project definition from the point of view of sustainability. However, the ideas found in the papers identified in Section 2 and treating the problem of improving project definition-even if detached from the sustainability concept-were used as a basis of the method developed in Step 2.

Step 2. Elaboration of a method of improving project definition in order to increase the sustainability degree of the project and by consequence, the project success probability, with stakeholders' involvement. Here, we used the grounded theory approach. Grounded theory $[39,74]$ is a systematic qualitative research method introduced by Glaser and Strauss in 1967. They defined it as "a way of arriving at theory suited to its supposed uses" [75]. Grounded theory is generated through the analysis of concepts and their interdependencies obtained from qualitative data. In our case, the qualitative data analysed were different approaches proposed in the literature to improve project definition, outside the sustainability contexts. An analysis of those approaches, juxtaposed with the role of sustainability in projects, gave rise to the main product of our paper: a method of improving project definition in order to increase the sustainability degree of the project. Our method was inspired above all by [37], where hidden fuzzy terms were defined, but also by [38] and [69], where the notion of "smells" in the wording of project definitions was introduced. These are terms which are not completely clear or not completely defined in the original version of project definition. The idea of the method is that in these places, the stakeholders, representing the three pillars of sustainability (TBL), are asked to express their preferences about various clarification or concretization scenarios of those terms, so that, once the inevitable moment comes, when such terms have to be made concrete and specific, a generally accepted compromise and a minimum (assumed) level of sustainability will be guaranteed.

Step 3. Qualitative research-verification of the method using the case study approach.

The proposed method will be initially verified, using a case study: an already completed project aimed at increasing the architectural accessibility of public buildings for disabled people (described in the next section).

According to [76] and [40], the case study method should be used when:

(a) the focus of the study is to answer "how" and "why" questions;

(b) it is impossible to manipulate the behaviour of those involved in the study;

(c) the contextual conditions are relevant for the study;

(d) the boundaries are not clear between the phenomenon and the context.

As the aim of the case study is to answer how ambiguities in project definition can be corrected with the objective of increasing the sustainability degree of the project, as well as to analyse these ambiguities in order to discover why they occur in the project definition (whether they are a mistake or the consequence of a lacking information or decision), condition a) can be considered fulfilled. Condition $b$ ) is fulfilled too- the project has been terminated and the authors of this paper have not contacted the stakeholders of the project since its closure. The contextual conditions are extremely 
relevant for the study, as sustainability is generally inseparable from the wider context of the project (condition c), especially when such sensitive issues as disability come into play. The boundaries between sustainability degree in the project and the context of the project (the numerous stakeholders, especially disabled people, and the whole problem of "disability" and "society") are highly fuzzy (condition d). Thus, the choice of the case study approach for the verification of the proposed method seems correct.

The literature on case studies [76] distinguishes various types of case study. We have decided to use a holistic case study, i.e., a case study where there is one unit of analysis [40]. This choice was of course dictated by the fact that we had unlimited access only to one project (one of the authors was among the experts of the project), but the literature says that this type of case study is particularly suitable for conceptual studies that verify the use of tools and methods in practice [40], thus also for the needs of this paper. The main form of data collection in the case study was analysis and interpretation of documents of the project (including Project Methodology, Application for Project Co-financing and Project Charter, which together build up the project definition), semi-structured interview with one of the project's experts (conducted during the preparation of this paper) and focus group interview with 15 members of monitoring teams (conducted immediately after the project closure), in order to compare project original definition with final project results. Based on the above data, a qualitative analysis was carried out, including the analysis of the wording of project definition, taking into account different project stakeholders and an attempt to answer the question to what extent the project was successful in the eyes of the stakeholders. The method elaborated in Step 2 was applied to the project definition and proposals of how the project definition should be modified in order to increase project sustainability were worked out. They were juxtaposed with the opinions of selected case study project stakeholders (project's expert and members of the monitoring teams) gathered after project closure. The potential usefulness of the method elaborated in Step 2 was assessed.

Step 4: Additional validation and verification of the proposed method.

On top of the case study, two other validation and verification methods were used. First of all, we made use of the method proposed in [41] for the validation of fresh concepts which have not been applied in practice yet. This validation method requires us to answer, with respect to the new concept, the following questions:

(a) to what degree is the concept "ingenious, imaginative or surprising"?

(b) to what degree is the concept radical or transformational?

(c) to what degree is the concept "socially, legally or politically acceptable"?

(d) how well can the concept be applied from a technical perspective?

(e) to what degree does the concept "apply to the problem at hand"?

(f) to what degree is the concept expected to solve the problem?

(g) to what degree is the concept "clearly, concisely and exactly defined"?

The answers to those questions permit us to have a clear picture of a fresh concept and indicate the directions for further research steps. We applied this approach to the validation of the proposed method.

We also made another verification attempt. We extracted from one real life project definition (the project was accepted for financing) from the European program "Life plus", including the project objectives and a short passage, which was clear to the reader even taken out of the whole project context. Then, we asked 6 researchers in project management and fuzzy modelling, who did not know our method or even its idea, to analyse the passage, asking them to indicate unclear and ambiguous places and explain what types of ambiguity or lack of clearness they see there, from the point of view of sustainability, and what dangers for project success they connotate for them. The aim of this validation step was to find out whether persons who are knowledgeable in project management, but have not been introduced to our idea, would see the necessity and usefulness of correcting project definition in order to increase project sustainability and to apply fuzzy sets in this context. 


\subsection{The Proposed Method of Analyzing and Modifying Project Definition}

The method proposed here searches for hidden fuzzy terms and "smells" in project definition, where:

- Hidden fuzzy terms [50] are notions which are implied by project definition, but are not present there in an explicit form. They should be inserted, but after insertion they may be still ambiguous;

- "Smells" [69] are notions which are present in the wording of the project definition, but are ambiguous.

In [37], it was proposed to introduce hidden fuzzy terms into the project definition. Then they become "smells", and are modelled by means of fuzzy numbers. However, the smells considered there were only adjectives or adverbs (big, small, sufficiently, etc.). They can be modelled as in Example 1 (see Appendix A) - the decision maker will be able to express his or her satisfaction with various numbers standing for a feature (width, length etc.). Here, we add the possibility of having collective nouns or categories as smells (see Example 2), e.g., the collective noun or category "institutions". To each collective noun, we can link a set of subcategories, e.g., the category "institutions" may be divided into subcategories "institutions of type 1, "institutions of type 2", etc., and the decision maker will be able to express his or her satisfaction with the cardinality (i.e., the number of elements) in each category or subcategory.

The basic idea of this method, expressed by the below algorithm, is thus as follows: the stakeholders representing each of the TBL sustainability pillars (social, economic and environmental) will be asked, first of all, to determine (informally) their expectations, especially the minimal ones, with respect to the projects. Then, they will be invited to read word by word the project definition and identify all ambiguities, unclarities or missing information from the point of view of the given stakeholder and the respective TBL pillar. In all such cases, the stakeholder will be asked to reflect on the elements which are unclear or absent from his or her point of view. Special emphasis should be put on the possibility (resulting from the unclarity or absence) of such a future interpretation of the corresponding place in the project definition which might not be satisfactory enough from the point of view of the stakeholder in question and the respective sustainability pillar. For example, the expressions "a certain number of some elements" or "a "big group" are smells which in the future might be interpreted in many different ways, which are not always satisfactory from the given point of view (see Example 1 and 2). Meanwhile, an expression like "select a measure to solve the problem" may be judged to contain a hidden fuzzy term, because each measure has certain features, like cost and effect, which are not mentioned in the expression "a measure". It may be interpreted in the future as the selection of a measure whose effect would be satisfactory for one stakeholder (e.g., representing the social pillar) but whose cost would be inacceptable for another stakeholder (e.g., representing the economic pillar). Additionally, an expression like "to select a group of elements" may be judged to contain a hidden fuzzy term, referring to its cardinality (see Example 2). Each stakeholder will be asked to identify such phrases and analyse them. If it is possible, he or she will be asked to indicate (or insert) adjectives, nouns and collective nouns which might be assigned a measure of satisfaction in the form of fuzzy sets, like in Examples 1 or 2. If this is not possible, a verbal analysis in an informal form should be delivered.

The results will be the project definition with corrections or remarks for these three groups of stakeholders, referring to unclarities or ambiguities, which they have identified from the point of view of the sustainability pillar they represent. Whenever it is possible to model a feature (like size, cardinality, cost etc.) by means of fuzzy sets, those fuzzy sets will be inserted and defined (by each stakeholder). The next step will be to accept and introduce crisp, inambiguous corrections which will be agreed upon by all the groups and to leave the places where there is a certain fuzziness for future negotiations and decisions. The places where fuzzy sets have been defined will allow for the formal measurement of sustainability, taking into account the weights assigned to individual stakeholders, and are therefore especially precious.

The algorithm concept is shown in Table 1: 
Table 1. Outline of the proposed algorithm aimed at increasing the project sustainability.

STEP 0: Identify the set of stakeholders important for the social aspect $S$, denoted as $S=\left\{T_{i}^{S}\right\}_{i=1}^{L_{S}}$, the set of stakeholders important for the economic aspect $E$, denoted as $E=\left\{T_{i}^{E}\right\}_{i=1}^{L_{E}}$ and a set of stakeholders important for the environmental (planet) aspect $P$, denoted as $P=\left\{T_{i}^{P}\right\}_{i=1}^{L_{P}}$. Assign weights $\left\{w_{i}^{S}\right\}_{i=1}^{L_{S}}$ (whose total is 1), $\left\{w_{i}^{E}\right\}_{i=1}^{L_{E}}$ (whose total is 1), $\left\{w_{i}^{P}\right\}_{i=1}^{L_{P}}$ (whose total is 1), respectively; STEP 1: Take the next stakeholder from the list;

STEP 2: Take the next closest potentially significant statement from project definition;

STEP 3: Ask the stakeholder the question: "Does the statement contain unclarities or hidden terms which might prevent the statement from being correctly understood or satisfactorily interpreted in the future, especially in relation to the TBL pillar in question?" IF yes, GO TO STEP 4; OTHERWISE GO TO STEP 2;

STEP 4: Ask the stakeholder to indicate all the unclarities and ambiguities, especially unclear or ambiguous features and unspecified cardinalities of collective nouns, where the satisfaction may depend on the perspective (the TBL pillar);

STEP 5: Has the end of the project definition been reached? If yes, GO TO STEP 6, OTHERWISE GO TO STEP 2; STEP 6: Has the last stakeholder in the list been considered? If yes, GO TO STEP 7, OTHERWISE GO TO STEP 1; STEP 7: Go back to the beginning of the document and analyse the corrections and insertions made by the stakeholders, and identify the places where they have identified features which in their opinion may be realised with different satisfaction degrees and where a fuzzy set can be defined (like in Example 1). Define the fuzzy sets together with the corresponding stakeholders;

STEP 8: Go back to the beginning of the document and identify, analogously to STEP 7, among the corrections and insertions made by the stakeholders, the collective nouns (standing for categories and subcategories) whose cardinality may be disputable (like in Example 2). Define the fuzzy sets together with the corresponding stakeholders;

STEP 9: STOP

The output of the above algorithm is a corrected definition of the project: completed with all the proposed corrections, remarks, insertions, made with respect to the three sustainability pillars, and-where possible - with preferences of each stakeholder defined in a formal way, by means of fuzzy sets. The idea of the proposed method is to carefully analyse the text of project definition from the point of view of each of the TBL pillars. The term "potentially significant" from STEP 2 means that "blah blah" type passages should be omitted, but each potentially significant expression should be taken into account. Each stakeholder for each of the TBL pillars should be asked whether he or she sees in the expression a full possibility to express his or her preferences and later to evaluate the outcome. If not, the identified missing information should be completed and ambiguous expressions ("smells") should be made more specific by means of stakeholder preferences.

Once the project is started, the places in the project definition which have been corrected/completed/commented in an informal way should be analysed in an informal way, but in all those places where preferences of individual stakeholders, representing respective TBL pillars, have been expressed by fuzzy sets, concrete values (realisations) should be taken. In each such place, the weighted satisfaction for each pillar can be calculated and then the total sustainability degree in the given project definition aspect, being e.g., the average or the minimum of the three satisfaction degrees, can be determined. If it is higher than a predefined threshold, the project can be continued; if not, negotiations with the participation of stakeholders have to take place until a compromise is attained.

Example 3: Let us consider a phrase in a project definition: "Construction of an entrance to the new office building". This expression is ambiguous, because it is not said whether it will be an entrance with a disabled ramp or with a lift and of which quality the two will be. So, as a result of the application of the above algorithm, this phrase would probably be completed with a few possible solutions, for simplicity lest us assume only four: $\left\{C H \_R, E X \_R, C H \_L, E X \_L\right\}$, where $C H \_R$ stands for a cheaper ramp, EX_R for a more expensive ramp, $C H \_L$ for a cheaper lift and EX_L for a more expensive lift. The stakeholders representing the economic pillar will assign a higher satisfaction degree to the cheapest solution, those representing the social pillar to the most comfortable one for the disabled persons and those representing the environmental (planet) pillar to the one which harms the environment the least (does not use non-recyclable elements etc.). Let us assume that the following satisfaction degrees are given in Table 2 below: 
Table 2. Satisfaction degrees of TBL pillars stakeholders in Example 3.

\begin{tabular}{ccccc}
\hline & Cheap Ramp & Expensive Ramp & Cheap Lift & Expensive Lift \\
\hline Economic & 0.8 & 0.2 & 0.7 & 0.3 \\
\hline Social & 0 & 0.7 & 0.3 & 0.9 \\
\hline Environment & 0.5 & 0.5 & 0.4 & 0.2 \\
\hline
\end{tabular}

If the economic pillar was the only one to make decision, a cheap ramp would have been built, not satisfying the social pillar even to the minimal degree. This decision might have been taken in a non-transparent way, because of the ambiguity and the missing information in the project definition. Applying our method first of all enforces transparency, which is one of sustainability postulates: representatives of each pillar have a chance to notice the danger of their insufficient satisfaction and explicitly introduce the missing information about possible scenarios and about their satisfaction degrees with various possible scenarios. They are noticed and feel respected, which automatically increases their satisfaction.

Then we can reflect on the aggregation of the various satisfaction degrees. Let us now calculate the minimal satisfaction degrees for each solution, and weighted averages. As for weighted averages, we can assign equal weight to all the pillars or assign e.g., weight 0.5 to the social pillar and 0.25 to the other ones. The results are given in Table 3:

Table 3. Various aggregations of satisfaction degrees in Example 3.

\begin{tabular}{ccccc}
\hline & Cheap Ramp & Expensive Ramp & Cheap Lift & Expensive Lift \\
\hline Minimum & 0 & 0.2 & $\mathbf{0 . 3}$ & 0.2 \\
\hline Average: equal weights & 0.43 & $\mathbf{0 . 4 7}$ & $\mathbf{0 . 4 7}$ & $\mathbf{0 . 4 7}$ \\
\hline $\begin{array}{c}\text { Average: weight } 0,5 \text { to } \\
\text { the social pillar }\end{array}$ & 0.32 & 0.52 & 0.42 & $\mathbf{0 . 5 7}$ \\
\hline
\end{tabular}

We can see that the cheap ramp would not be chosen in any of the above cases. The cheap lift is the best choice in two of the above cases, so it is probable that this decision would be taken in a transparent decision-making process, enforced by our method. This choice would ensure that all 3 pillars would be taken into account and the satisfaction with the outcome of all the stakeholders would count.

The method proposed by us gives a more complete and more sustainable project definition in the sense of making explicit all the possible conflicts in satisfaction degrees of stakeholders representing the three TBL pillars. It also enforces transparency in decision making. The next section will present a real-life project by means of which we try to initially verify the practical need for our method.

\subsection{The Case Study Project}

\subsubsection{Description of the Project}

The project to be analysed here aimed at analysing the tasks carried out by government and self-government administration units and developing recommendations/guidance for adapting their activities to the provisions of the UN Convention on the Rights of Persons with Disabilities (CRPD). This project was financed under the Operational Program Knowledge Education Development and was implemented from April 2017 to March 2019 in Lower Silesia, Poland. Its minimum assumptions and course were set out in the Project Methodology prepared by the Ministry of Labour and Social Policy (acting as the institution commissioning the implementation of the project through an open competition, supervising the correct implementation of the project recommendations and monitoring the achievement of indicators assumed in the project). Its actual implementation in Lower Silesia, 
Poland, was undertaken by a non-governmental organization (called in the following Organisation X) selected in a competition, experienced in activities for the benefit of people with disabilities.

Due to the large amount of data collected during the project and their diverse nature, for the purposes of this paper it was decided that we should focus on one of the project tasks-an audit of the architectural accessibility of selected buildings. This task was carried out by five monitoring teams, assisted by people with disabilities, acting as experts. The task's start date was originally set to March 1 2018. The end of the task was planned for November 30 2018. However, difficulties in implementing the audit meant that the task was completed only on March 1, 2019.

The purpose of the audit was to assess the current status and architectural availability requirements in the following areas: the surroundings in front of the building; the interior of the building and access to information. The monitoring teams, using a research tool included in the Project Methodology - the accessibility matrix — carried out a monitoring visit in each of the buildings selected for the audit. The audit's purpose was to determine the actual state and propose recommendations whose implementation would improve the level of architectural accessibility of the monitored objects. These recommendations could include activities of varying degrees of difficulty or cost-effectiveness ratio. The "simpler" measures (implicitly of no or low cost and easier to implement) were to be implemented during the project. More complicated recommendations, requiring e.g., external financing, changes in the budget of the monitored unit, legal changes or extended implementation time, could be qualified as necessary for implementation after the end of the project. In addition, these recommendations could be implemented in accordance with, partly in accordance with, or contrary to the suggestions of the monitoring teams, which could, if necessary, provide substantive support in implementing the recommendations.

\subsubsection{Initial Evaluation of the Project Implementation and Outcome}

A significant problem in the project was the lack of clear guidelines as to the number of recommendations needed to be implemented during the project. The project methodology did not contain any guidelines in this regard. It was only during the implementation of the project that the Ministry of Labour and Social Policy determined that it was necessary to implement at least one recommendation in each of the areas (and therefore also in the area of architectural accessibility), while it did not specify any requirements regarding the quality or validity of the recommendations in relation to the project objective. Therefore, the organization implementing the project, taking into account not only the project goal, but also its own reputation and delays in project implementation, determined that it was necessary to implement between 1 and 5 recommendations for each of the areas in each monitored unit. On the other hand, the team of experts employed by this organization, caring for the level of project implementation and responsible for monitoring the quality of monitoring teams' work, determined that it was necessary to implement between 1 and 3 recommendations for each of the areas in each monitored unit. The difference between the organisation's management board guideline and the expert guideline resulted from the difference in the assessment of the potential of the monitoring teams and the difference in the assessment of the possibilities of implementing the assumed recommendations by the monitored units. It should be emphasized that the management board of the organization had advanced knowledge regarding activities for people with disabilities, while the team of experts had advanced knowledge of the functioning of government and self-government administration units, management and research units.

The audit of architectural accessibility during the project duration covered 50 randomly selected institutions. They were: Voivodeship Office, Marshal's Office, combined administration operating at voivodeship level, commune offices and county offices. For each of these institutions, buildings were selected, which became the subject of the audit. The audit procedure required visiting all buildings and assessing, by means of a dedicated research tool, their functionality in terms of accessibility for people with various disabilities. Based on the data collected during the audits, the monitoring teams worked out appropriate recommendations, which, after consulting the representatives of the monitored unit, 
were assigned the status of possible implementation during the project implementation or after its completion. The product of this process was a monitoring report, also containing recommendations in the field of architectural audits, presented for approval by the monitored institution. After accepting the report, the institution had time to implement the recommendations. It was originally assumed that the monitored units will have between 4 and 6 months to implement the recommendations. However, due to delays in project implementation, in extreme cases this time was significantly reduced, which affected the quality of recommendations, understood as their weight and importance in relation to the main goal of the project.

On the formal side, the project finished in achieving the indicators assumed by the Ministry. In each of the examined units, in relation to each of the monitored areas, during the project at least one recommendation proposed by the monitoring team was implemented. However, these recommendations were very diverse. Some of them were recommendations were solely intended to meet the need to achieve project indicators, e.g., recommendations referred to as "increasing the readability of information placed in the building space" meant simply that announcements were printed out in larger font. In addition, considering the project's goal, i.e., developing recommendations/guidelines in terms of adapting the activities of the monitored institutions to the provisions of the UN Convention on the Rights of Persons with Disabilities (CRPD), there was an insufficient consideration of the key stakeholder group of this project, i.e., persons with disabilities themselves. The failure to verify the recommendations by the persons they were designed for may question not only their quality but also their purpose, which in the context of the CRPD's assumptions is contrary to the objectives and principles of sustainable development.

\subsubsection{Project Stakeholders}

Generally, we have to state that stakeholder management in the project in question was far from sufficient. Many key stakeholders did not have the chance to clearly express their preferences and the overall actual success of the project, abstracted from the formal one, is less then modest.

Additionally, there did not exist an exhaustive list of important stakeholders. We can post factum deduce the following (by far not complete) lists. There would be two of them:

- one would refer to the most important stakeholder group of the project, the disabled persons, which will be linked to the social pillar of TBL;

- the second one would refer to the institutions selected for monitoring, where the decisions provide measures which are "simple or difficult to implement", "low cost or expensive" etc., were taken, which would refer to the economic pillar of the TBL;

Unfortunately, the third pillar of the TBL, the environmental or planet-related one (referring to issues like the raw resources selected, avoiding people abuse etc.) was completely absent in the project, which is intrinsically wrong.

Here are example lists of the two stakeholder groups, identified in an interview with an expert during the preparation of the paper:

\section{Stakeholders representing the interests of the disabled people (these stakeholders might represent the social aspect of the TBL pillars):}

1.1 The disabled persons themselves

1.2 The nearest environment of the disabled persons (relatives, friends, legal guardians)

1.3 Plenipotentiaries of disabled persons

1.4 Non-governmental organisations

1.5 Various administration and local government units dealing with disabled persons

1.6 Ministry of Labour and Social Policy

1.7 Organisation $\mathrm{X}$. 
2. Stakeholders representing the interests of the institutions selected for monitoring (these stakeholders might represent the economic aspect of the TBL pillars):

\author{
2.1 Village mayors; \\ 2.2 Voivodeship marshal; \\ 2.3 Department heads of the monitored institutions.
}

Unfortunately, the interests of all these and possibly other stakeholders have not been systematically and rigorously balanced, which became clear in the above description of the project course. Many of the stakeholders from the above lists did not have a chance to describe their preferences. Some of them had the chance but did not use it or used it only at the end of the project and not at the very beginning, when this would have been indeed necessary. On top of this, we can notice evident conflicting interests (assessing the cost of a measure against its usefulness for the disabled persons) and divergent objectives (see the various objective numbers of recommendations to be implemented-while that the Ministry in each category was sufficient, the other stakeholders definitely required a higher number).

This is the story told by a project participant: "Organization X, based on the Project Methodology, had to first prepare an extensive application for project co-financing, which was the subject of the competition procedure, which was then transferred into a project chart, enabling project management. At this stage, it turned out that the objectives set out in the Project Methodology, along with the indicators set for their implementation, were not easily operationalized".

According to one of the authors of the present paper, who participated in the project as an expert, the project was far from being a success, although formally it was evaluated as such. The statement that the project was not really successful can be translated into the following sentence: "The project, and especially its product, was not sustainable enough" — even if we assume that the "planet" dimension, completely ignored in the project, was not of high importance here.

In our opinion, a systematic method analysing project definition, whose sketch was given in Section 3.2, would have increased the sustainability, and thus the actual success of the project. It would have forced Organisation $X$ to also take into account the environmental aspect. What is more, there is a large chance that the approach would have been accepted by all the parties involved, because, in fact, our approach was, although unconsciously, informally and in a very rudimentary form, in fact applied (see Section 4.1).

The results of the application of the method from Section 3.2 to the case study project will be discussed in the next section.

\title{
4. Results
}

The objective of this section is to verify potential usefulness, applicability and acceptability of the method from Section 3.2. Section 4.1 represents an initial verification of the acceptability: it shows that our method actually was, unconsciously and of course only partially, applied to the project in question. Section 4.2 presents the potential usefulness of the method: through a post factum application of our method, we show that it would have led to a project definition which would guarantee a higher level of sustainability degree of the project than the actual one, which constitutes an initial verification of the hypothesis formulated in the Introduction. Of course, our method has not been verified a priori in real world conditions yet. That is why in Section 4.3, we apply to our proposal a validation method dedicated to a fresh concept, not tried out in practice yet. Section 4.4 delivers additional arguments for the usefulness and potential acceptability of the method: an excerpt from another real-world project definition has been submitted to analysis by several project management and fuzzy modelling experts. They were asked to apply the proposed method to this excerpt and identify unclarities, ambiguities etc. They were also supposed to express their opinion on the fuzzy modelling of the identified unclarities and ambiguities and on the potential usefulness of the proposed approach. 


\subsection{Analysis of Changes Actually Introduced into the Initial Project Description}

The initial project description is called here the "Project Methodology", and the final project description, which was then used as the basis for project management, is called the "Project Chart". As we mentioned above, the two documents actually existed in the case study project. The Project Chart was the effect of corrections introduced into the Project Methodology. Selected differences between them are shown in Table 2 and discussed afterwards.

The rectangles in Table 4 mark the differences between the first and the second project definition. Among those changes (all of them were introduced by Organisation X), we can find four evident cases of filling in missing information: inserting the information about the number (50) of institutions to be monitored (thus a fuzzy adjective has been made precise- - a sufficient number of institutions), about the voivodeship, where the project was to be implemented, about the deadline and about the expected results. The other two changes are "smells" corrections: the word "strengthen" seemed to Organisation X not clear enough and the article "the" in the last row could lead to ambiguity too-it is not clear whether one single change is meant or more of them.

Table 4. Comparison of key assumptions of the Project Methodology and the Project Chart.

\begin{tabular}{ccc}
\hline CATEGORY & PROJECT METHODOLOGY & PROJECT CHART \\
\hline Main aim & $\begin{array}{c}\text { Strengthening the capacity of the monitored } \\
\text { institution for implementation of the UN } \\
\text { Convention on the Rights of Persons with } \\
\text { Disabilities by analysing the activities of the } \\
\text { institution, formulating recommendations } \\
\text { regarding the institution's activities and } \\
\text { verifications of their use. }\end{array}$ & $\begin{array}{c}\text { Increasing the capacity of } 50 \text { monitored } \\
\text { institutions-in the Lower Silesia } \\
\text { Voivodeship-to implement the provisions of } \\
\text { the UN Convention on the Rights of Persons } \\
\text { with Disabilities by analysing the activities of } \\
\text { the institution, formulating recommendations } \\
\text { regarding the institution's activities and } \\
\text { verifying their use until 03.2019. }\end{array}$ \\
\hline Result & Undefined in Methodology & $\begin{array}{c}\text { Implementation of recommendations } \\
\text { resulting from monitoring by } \\
\text { 25 monitored units. }\end{array}$ \\
\hline Recommendation & $\begin{array}{c}\text { The proposed change in the activity of the } \\
\text { monitored institution, aimed at increasing its } \\
\text { capacity to implement the provisions of the } \\
\text { UN Convention on the Rights of Persons with } \\
\text { Disabilities. }\end{array}$ & $\begin{array}{c}\text { Any proposed change in the activity of the } \\
\text { monitored institution, aimed at increasing its } \\
\text { capacity to implement the provisions of the } \\
\text { UN Convention on the Rights of Persons with } \\
\text { Disabilities. }\end{array}$ \\
\hline
\end{tabular}

This example shows that the project definition has to be analysed carefully and that there is a need for such an approach between practitioners. However, in the process described here, only one single stakeholder participated (Organisation X), which is inconsistent with the idea of project success and project sustainability management. On top of that, no systematic and formal approach was used. Let us now analyse where our approach might have led to.

\subsection{Post Factum Simulation of the Method Application}

The document from the right-hand part of Table 3 has been subjected-post factum, after project completion-to the method from Section 3.2. Below, we can see selected words (important from the point of view of method application) from the text from the right hand column of Table 3 with comments suggesting how the algorithm from Section 3.2 might work here:

Institutions Here we deal with a collective noun, for which various subcategories $\left\{C_{t}\right\}_{t=1}^{T}$, of institutions were selected (during the preparation of this paper, in an interview with an expert who participated in the project):

- one possible subdivision into subcategories: Voivodship Office, Marshal's Office, administration operating at voivodship level, commune offices and county offices;

- another possible subdivision: according to various locations. In the different locations disabled persons may live in communities of various sizes; 
- $\quad$ another possible subdivision: according to the present degree of accessibility.

The project description should be completed with corresponding fuzzy sets $\left\{\left\|\widetilde{C}_{t}\right\|\right\}_{t=1}^{T}$ expressing the preferences of individual stakeholders with respect to the total number of institutions selected for monitoring and the number of institutions in individual categories. Then, the weighted satisfaction by the "social" and "economic" stakeholders would be calculated (here, no "planet" stakeholders were identified). In the project, according to the testimony of the expert, the institutions were selected randomly, thus their representativeness was not taken into account. Such an approach cannot guarantee a sufficient satisfaction both of the "social" and the "economic" stakeholders. The sustainability degree here would be totally uncontrolled and purely random.

Activities: Which activities? How selected? How many of them? These are some of possible questions which could have or should have been asked by the stakeholders. In addition, here the important thing is the number of activities considered and the number of elements in various subcategories. Three subcategories identified in the interview with the expert were:

- $\quad$ architectural features: physical accessibility (ramp, location of reception desk, width of corridors and entrances, equipment of bathrooms);

- $\quad$ service of blind persons;

- $\quad$ service of deaf persons.

Expressing preferences as to the cardinality of various categories in the two groups of stakeholders and calculating their weighted satisfaction with the choice of activities for monitoring would guarantee that the stakeholders with a high weight, e.g., the disabled people, would have more influence on the choice of activities to be monitored.

Recommendation: Any proposed change (... ) aimed at increasing capacity to implement... Here we deal with the noun "change", which has certain features, unmentioned (i.e., "hidden") here. The words "any change, aimed at increasing" are ambiguous. We know-from the interview with the expert - that changes of little value for the disabled people were introduced as a project result. Thus, here we would propose to define a set of pairs of features describing each change: $(a, b)$, where $a$ is selected from the set of expressions \{increasing the capacity to a tiny degree, to a small degree, to a middle degree, to a high degree, to a very high degree\}, and $b$ from the set of expressions \{very cheap, cheap, of average price, expensive, very expensive\}. Each stakeholder would define his or her satisfaction with each of the couplse $(a, b)$, by means of fuzzy numbers defined on the set of those couples. For example, a fuzzy set might be defined by a stakeholder representing the economic pillar in the following way: $Z_{A}=$ $\left\{\left(a_{1}, b_{1}\right),\left(a_{2}, b_{2}\right)\right\}$, where $a_{1}=$ increasing the capacity to a tiny degree, $a_{2}=$ increasing the capacity to a high degree, and $b_{1}=$ very cheap, $b_{2}=$ very expensive, $\mu\left(a_{1}, b_{1}\right)=0,8, \mu\left(a_{2}, b_{2}\right)=0$,2. A stakeholder representing the social pillar will certainly attribute other satisfaction values to the elements of $Z_{A}$.

Then, when ultimate decisions in the project are taken, the minimal or weighted satisfaction with each decision in each group of stakeholders would be calculated. If the satisfaction was insufficient in one of the groups, e.g., in the "social" group, e.g., with the abovementioned measure consisting of changing the size of characters in announcements put on the bulletin boards, the change would not be accepted. In this way, the sustainability degree of the project, measured by the satisfaction of the stakeholders representing the social and economic pillar, would have been higher, which partially verifies the hypothesis formulated in the Introduction. The hypothesis stating that a systematic reading, correcting and completing of an existing project definition might increase the sustainability degree of the project, and thus its success probability, cannot be rejected at this stage.

In the analysed case study, the stakeholders were not systematically asked about their preferences and this may be the main cause of the lack of actual project success, and of the fact that public money obviously was not spent efficiently. If the first group of stakeholders-identified in Section 3.3.3-had been asked to act according to the algorithm, the project chart would have been more flexible and would have assured a much higher sustainability of the project outcomes. The stakeholders (especially 
the disabled persons) would have felt more important, and the sustainability principles like traceability and accountability would have been fulfilled to a higher degree. Additionally, the environmental aspect would have been taken into account-in this case, it was completely disregarded, which is highly incorrect in a project paid by the society.

It has to be underlined that even in our analysis presented here, various important aspects of sustainability, such ass the problem of resource usage, human abuse or numerous global aspects, have not been taken into account. Thus, the project chart should have been analysed even more thoroughly in order to ensure full project success in terms of sustainability.

\subsection{Initial Validation of the Method as a Fresh Concept}

It has to be stated clearly that the algorithm proposed in this paper is an initial concept which has not been applied a priori in practice yet. Even if initially promising-as shown in Sections 4.1 and 4.2-it needs further verification. In [41], we find a method for the validation of fresh concepts which have not been applied in practice yet. This validation method was presented in Section 3.1 (Step 4). It requires answering, with respect to the new concept, seven questions (see Section 3.1). The answers to those questions permit us to assess the fresh concept. The higher the total score, the better developed and the more promising the fresh concept is.

Let us try to answer these questions for our method (proposed in Section 3.2) in the scale from degree 0 ("not at all") to degree 5 ("completely). It has to be underlined (which unfortunately limits the value of the validation) that the answers were given by the authors of the present paper. However, an effort was made to formulate, as far as it was possible, objective answers.

(i) The proposed concept is "ingenious, imaginative or surprising" to a medium degree, but still can be considered as fairly surprising, because no scientific papers were identified which have proposed analysing and modifying the project definition with the participation of the stakeholders with sustainability in mind (degree 2.5);

(ii) The concept is to a medium degree radical and transformational, as it completely changes the ways in which various stakeholders should participate in defining the project. In the focus group interviews (with members of the monitoring teams) after the case study project completion, it was underlined that many institutions taking part in the project did not employ any expert from the domain of disability. The algorithm would have forced them to find such an expert (degree 2.5);

(iii) In our opinion, the concept is "socially, legally or politically acceptable" to a rather high degree, although in the focus group interviews, after the completion of the case study project, it was underlined that in many public institutions, the project was considered to be "necessary, but not extremely important or urgent". Thus, the acceptability of the sustainability, and thus of the proposed method, may still be not high enough in certain organisations. However, in the focus group interviews of the case study project, we also obtained the testimony that the project goal and definition were "unclear". This indicates high chances for the method's social acceptability (degree 3);

(iv) From the technical perspective, the concept still needs a lot of research in order to be applicable. It has to be tested on many case studies and in many different environments and it needs software support and a lot of training of managers and other stakeholders (degree 1);

(v) The problem at hand is the fact that incorrect project definitions prevent projects from giving sustainable outcomes. The concept directly refers to this problem (degree 4);

(vi) The concept is able to solve the problem to a high degree if the algorithm becomes technically applicable and generally accepted by all the parties involved, but of course the algorithm is not sufficiently developed yet (degree 1);

(vii) The concept is not yet "clearly, concisely and exactly defined". We proposed an initial approach to correcting and completing project definitions and introducing formal satisfaction measures by various stakeholders wherever possible, but a lot of further research is still needed here (in terms 
of text analysis, types of corrections, fuzzy modelling, dialogue with non-mathematicians etc.) (degree 1).

The average score is 2.1 , with 5 being the maximal score: the concept seems promising, but still requires further development.

\subsection{Initial Verification of the Method Using Another Real World Project}

For this step of verification, the project ADAPTCITY (accepted for funding) from the European program "Life plus" was selected. Its general goal was formulated as the "Preparation of a strategy of adaptation to climate change with use of city climate mapping and public participation". We selected the following excerpt from its definition, making sure that the notions mentioned in this excerpt were not explained in the further part of project definition (see Table 5).

Table 5. Excerpt from the definition of project ADAPTCITY submitted to the application of the proposed algorithm.

1. Preparation, on the basis of the climate map and in a participative process involving various social groups
(citizens, with special focus on the elderly and the youth, non-governmental organisations, business etc.), of a
climate adaptation strategy for the metropolitan area of Warsaw.
2. Wide promotion of a climate change adaptation issue in Warsaw and in other cities of Poland through the
dissemination of climate map for Warsaw in the Internet and the local press, the organisation of many local
meetings, preparation of a training movie, information tables and an education programme based on their content.

Six researchers in project management, who did not know the idea of the present paper but were knowledgeable about fuzzy sets, were asked to indicate in the above texts unclarities, ambiguities and hidden fuzzy terms, which might lead to such an interpretation of the text that the project would be judged as formally successful, but actually would not satisfy certain stakeholders.

The first conclusion of the experiment is that all of the participants clearly saw the necessity of a correction of the project definition. Remember that this was the definition of a project which was assigned financing by the European Union-thus we are not dealing here with an accidental second class project definition. The average number of corrections or insertions proposed was 7.5 , the minimal 5 , the maximal 10. It has to be added that most corrections or insertions proposed were rather complex and would have involved many single corrections/insertions. Below, in Table 6, we list the corrections or insertions which were proposed by at least four participants.

Table 6. Unclarities, ambiguities, hidden fuzzy terms indicated by the experiment participants, which might endanger project success from the point of view of some stakeholders.

\begin{tabular}{|c|c|}
\hline Words from Table 5 & Feedback from the Participants \\
\hline "various social groups" & $\begin{array}{l}\text { Which social groups? How many of them? With how many } \\
\text { participants each one? }\end{array}$ \\
\hline "the elderly and the youth" & $\begin{array}{l}\text { What do these notions mean? How many representatives of } \\
\text { each group? }\end{array}$ \\
\hline "non-governmental organisations" & $\begin{array}{l}\text { Which ones? Of which profile? Of which size? How many in } \\
\text { each category? }\end{array}$ \\
\hline "other cities of Poland" & $\begin{array}{l}\text { Which ones? From which parts of Poland? Of which number } \\
\text { of inhabitants? How many in each category? }\end{array}$ \\
\hline "many local meetings" & $\begin{array}{l}\text { Where organized? What does it mean "many"? With how } \\
\text { many and what type of participants? }\end{array}$ \\
\hline
\end{tabular}

All the observations made by the experiment participants refer to the balance between the social and economic pillar: if researchers examine more "social groups", bigger "social groups" or organize more "local meetings" etc., they will incur higher costs, but at the same time, they will be able to 
take into account the opinions and preferences of a more representative sample of the society. It is clear that a compromise has to be achieved. The possibility for the stakeholders representing the two pillars to express, by means of fuzzy numbers, their minimal and maximal expectations in each aspect will ensure that during project realisation a compromise will be worked out which at least will not compromise the minimal expectations of the two stakeholder groups. In this way, the sustainability degree of the project will be kept at the required minimum, which verifies to a certain extent the hypothesis formulated in the Introduction.

The experiment participants (knowledgeable about fuzzy modelling) did not have time for a formal definition of respective fuzzy sets, but in informal conversations they said that they would be a natural and fairly easy to use and acceptable tool for the formal measurement of the satisfaction of various stakeholders with the different aspect of project realization and outcome. For example, fuzzy sets might express the stakeholder satisfaction with the cardinalities of individual sets (e.g., with the number of participants selected in each "social group") or his or her understanding of the notions "elderly" or "young". The experiment proves that the hypothesis saying that a systematic reading, correcting and completing of an existing project definition will increase the sustainability degree of the project, and thus its success probability, cannot be rejected.

\section{Conclusions}

In this paper, using the case study and literature review method, we have shown that a systematic approach to improve the quality of project definition would be needed in order to improve project success probability, if (and this is what the modern approach to defining project success assumes) project success to sustainability-which comprises a balanced satisfaction of stakeholders representing the TBL pillars.-is assumed.

Introducing sustainability into project definition should ideally be an essential part of project creation and management from the very beginning, from the project idea's birth. However, given the reality, when project applications are often compiled in a hurry by dispersed co-authors, and no systematic methodology of formulating "sustainable" project definitions exists, there is a need for a method of reviewing and modifying existing project definitions, in order to increase the project's sustainability degree, and thus success probability. This was the research problem we identified. Our objective was thus to propose a method for project definition modification which would increase project sustainability degree. The method is sketched and then applied to a real-world project. Using the case study project, we justify the need for the method and its potential usefulness. Using another real-world project, we deliver an additional verification of the potential usefulness and acceptability of the method.

Our method will impose on project organisation to identify, in the project definition (initiation) stage, project stakeholders representing all the three TBL pillars. The stakeholders will be required in their turn to reflect on the type of expectations they have with respect to the project within "their" pillar and on the extent of compromise they will be ready to accept. It will be necessary to do so, because the method expects that the stakeholders examine all the words and formulations in the project definition, searching for missing or ambiguous requirements (from the perspective of their pillar). In each identified incomplete or ambiguous passage of project definition, the project stakeholders will be asked, if possible, to put a fuzzy number expressing their satisfaction degree with various scenarios, which will make it possible to build compromises and measure the total (weighted or minimal) sustainability degree of the project. Such a reflection will enhance the acquaintance of the stakeholders with the project, enforce their consciousness of their requirements from the point of each TBL pillar and increase the chances to attain at least a minimal degree of satisfaction in all the TBL pillars, thanks to a fuller and clearer project definition, as well as thanks to an early started communication among project stakeholders on project success. Additionally, the mere fact of participating in the process of defining the project increases the satisfaction with project outcomes [36]. 
From the theoretical point of view, our method is an extension of existing methods of identifying so called "smells" and "hidden fuzzy terms" in existing project definitions. The main novelty with respect to the literature is the introduction of different stakeholder groups and the necessity of balancing their-often conflicting-views. In the methods known from the literature, the stakeholders are not identified, and only the customer is taken into account. What is more, the existing methods were referred only to IT and construction projects, whereas our method can be applied to any project. It should be underlined that our method of project definition analysis is the first one in the literature which takes sustainability into account.

Of course, the proposed method has numerous limitations. First of all, it does not lead to a ready and ideal project definition. Its outcome is merely a modified project definition with numerous annotations coming from the stakeholders representing the three TBL pillars with a formal measure of satisfaction in the form of fuzzy sets in those places of the project definition where it was possible. Thus, the outcome of the method is merely an improved project definition, with identified unclarities and ambiguities and the possibility of a formal measure of sustainability degree (in each of the three sustainability pillars) in some of its passages. This modified project definition, as shown by the two real-world projects, guarantees a much higher stakeholder participation and thus a much higher sustainability degree and success probability, but does not exclude further misunderstandings or unnoticed ambiguities. Secondly, the application of the method requires a lot of effort. There should be a coordinator of the whole process and all the key project stakeholders in all the TBL pillars would have to consecrate a considerable amount of time to the careful analysis of the project definition. Before that, they would have to reflect deeply on their expectations and compromise possibilities with respect to project sustainability. On top of that, they would be asked to express, if possible, their preferences in a formal way. Thus, all of them would have to be introduced to the usage of fuzzy sets for satisfaction expression and measurement. Numerous other limits of the method are pointed out in Section 4.3, where the method is validated using a validation method for fresh concepts. Because the method is indeed a fresh concept, it has never been applied thoroughly and a priori to a whole project, with the active participation of its key stakeholders. Many more case studies are needed to verify and improve the method.

In the authors' opinion, the method may be applicable to any project, but some project types may find it more useful and some less. Obviously, there are projects which have smaller social and environmental impacts than others. Most IT projects influence the environment and the society less that e.g., big construction projects, which destroy forests in order to build a road, and less than most social projects, whose mere sense of existence lies in attaining social objectives. For such projects, satisfying the social or environmental pillar may be less important. However, we have to take into account that each project consumes human resources and has some impact on humans. Sustainability means also not exploiting project team members, which has to be taken into consideration in almost every organization and project [2]. So, in our opinion, the method may contribute to the success of any project, and the weights in the algorithm from Section 3.2 should be simply selected accordingly for each of the TBL pillars.

A practical, systematic application of the proposed approach will obviously encounter many obstacles. A very serious one would be the lack of many stakeholders' attention regarding the sustainability issues, the importance of stakeholder commitment and insufficient abilities in soft skills [7]. In [77], we can read that sustainable development requires the cooperation of various actors, in all their complexity and diversity. This may not be easy in practice.

The proposed concept, apart from testing in real world situations, needs further theoretical development, e.g.,:

- multicriteria and fuzzy ranking methods have to be applied to enable aggregated assessment of project outcomes (real ones or simulated) (per one stakeholder and/or per one outcome or a collective evaluation); 
- sustainability in all its various dimensions should be integrated: not only the three TBL pillars should be used, but also other aspects, like the usage of resources (human and material ones), transparency etc.

Nevertheless, it seems clear that projects and their products simply have to be sustainable today, otherwise it is not possible to call them successful. Society requires sustainable acting, and project sustainability cannot be achieved without a new approach to project definition. We hope our paper will open a research path leading to powerful solutions in this aspect.

Author Contributions: Conceptualisation D.K. and J.M.-C.; Investigation J.M.-C.; Formal analysis D.K.; Writing-original draft preparation D.K.; Writing-review and editing J.M.-C. All authors have read and agreed to the published version of the manuscript.

Funding: This work was supported by the National Science Center (Poland), under Grant 394311, 2017/27/B/HS4/01881: "Selected methods supporting project management, taking into consideration various stakeholder groups and using type-2 fuzzy numbers".

Acknowledgments: In this section you can acknowledge any support given which is not covered by the author contribution or funding sections. This may include administrative and technical support, or donations in kind (e.g., materials used for experiments).

Conflicts of Interest: The authors declare no conflict of interest. The funders had no role in the design of the study; in the collection, analyses, or interpretation of data; in the writing of the manuscript, or in the decision to publish the results.

\section{Appendix A Basic Notions Concerning Fuzzy Sets}

Fuzzy sets, introduced in [78], are meant to express preferences, uncertainty or individual understanding of certain notions.

Definition 1. A fuzzy set $\widetilde{A}$ is a couple $\left(Z_{A}, \mu_{A}\right)$, where $Z_{A}$ is a set of objects of any type and $\mu_{A}$ is a function (called membership function) defined on $\mathbf{Z}_{\boldsymbol{A}}$ with values in the interval $(0,1) . \mathbf{Z}_{A}$ defines all the objects or all the values which may occur. Value $\mu_{A}(z)$ for $z \in \mathbf{Z}_{A}$ can be interpreted in various ways, among others, as the satisfaction of the decision maker with the occurrence of $z$. The higher $\mu_{A}(z)$ is, the higher the satisfaction of the decision maker with the occurrence of $z$. Another interpretation of $\mu_{A}(z)$ may be the degree to which, according to the decision maker, $z$ adequately represents a certain notion.

For an adjective $A, \widetilde{A}$ can define preferences of the decision maker as to various values or realisations of this adjective, and for a noun, with various realisations of the features which are linked to it. For example, if we consider the phrase "a long room", we can use fuzzy sets to define our satisfaction with various values of the room length, expressing at the same time our understanding of the word "long" in the given context. $Z_{A}$ can be the set of all the possible values of the length and $\mu_{A}$ would determine the satisfaction of the decision maker with the different values. If we consider the noun "room", we have to identify the features of the room which are of importance to us (like "length", "width" and "height") [37]. Then we can define by means of fuzzy sets the expressions like "sufficiently long" or "appropriate length". If we encounter a noun in the text, there may be hidden (i.e., not explicitly mentioned [37]) adjectives linked to it. For example, the noun "room" will always have certain features important for the decision maker, like length, width and height, even if they are not mentioned explicitly. These adjectives have to be identified and preferences with respect to them specified. Also, if we encounter in the project definition a notion like "elderly people", we might ask the decision maker to define for each possible age value the degree to which he or she thinks it corresponds to the notion "elderly".

Example 1. Let us consider the noun "room" and the case when the length is its most important feature. Let $\mathbf{Z}_{\boldsymbol{A}}$ be the set $\{4,5,6,7,8\}$, representing all the possible values of the length of the room. $\widetilde{A}$ can be then defined by the decision maker (the end user) as e.g.: $\mu_{A}(4)=0,2, \mu_{A}(5)=0,4, \mu_{A}(6)=1, \mu_{A}(7)=0,6, \mu_{A}(8)=0,3$, which would mean that the decision maker definitely prefers length 6 , all the other possible lengths being to some 
extent satisfying too, but values 4 or 8 are satisfying to a very small degree (the room would then be, in the eyes of the decision maker, either too short or too long).

We will also be interested here in collective nouns, thus those standing for a category. Let us consider a category $C$, representing the set of certain objects. It has an important feature: the cardinality. Then, we will consider the fuzzy set $\widetilde{\| C} \|$, representing the satisfaction of the decision maker with the number of elements in $C$. If a certain number of subcategories $\left\{C_{t}\right\}_{t=1}^{T}$, such that $\cup_{t=1}^{T} C_{t}=C$, can be associated with $C$, analogous fuzzy sets $\left\{\widetilde{\left\|C_{t}\right\|}\right\}_{t=1}^{T}$ can be defined, expressing the satisfaction of the decision maker with the number of elements in $C_{t}, t=1, \ldots, T$.

Example 2. Let us define $C$ as the set of all enterprises selected for a research, and let $C_{1}$ be the subset of enterprises from one county, $C_{2}$ - the set of enterprises from another county and $C_{3}$ - the set of enterprises from a third county. The decision maker can define $\| \boldsymbol{\| C}$ in such a way that $\mu_{\|C\|}(x)$, where $x$ is the number of all the enterprises selected for the research, takes on value 1 for $x$ greater than 100 and 0 for $x$ lower than 50 and it is stepwise increasing in-between. The two threshold values for $\left\|C_{t}\right\|, t=1,2,3$, might be e.g., 15 (the decision maker is completely dissatisfied if less than 16 enterprises are selected from one county) and 50 (the decision maker is completely satisfied if at least 50 enterprises are selected from one county). Of course, we would have distinctive decision makers for each county and their preferences would be conflicting.

\section{References}

1. Aarseth, W.; Ahola, T.; Aaltonen, K.; Økland, A.; Andersen, B. Project sustainability strategies: A systematic literature review. Int. J. Proj. Manag. 2017, 35, 1071-1083. [CrossRef]

2. Armenia, S.; Dangelico, R.M.; Nonino, F.; Pompei, A. Sustainable Project Management: A Conceptualization-Oriented Review and a Framework Proposal for Future Studies. Sustain. 2019, 11, 2664. [CrossRef]

3. Labuschagne, C.; Brent, A.C. Sustainable Project Life Cycle Management: the need to integrate life cycles in the manufacturing sector. Int. J. Proj. Manag. 2005, 23, 159-168. [CrossRef]

4. Goedknegt, D. Sustainability in Project Management: A case study at University of Applied Sciences Utrecht. PM World J. 2012, 1, 1-18.

5. Martens, M.L.; Carvalho, M. Key factors of sustainability in project management context: A survey exploring the project managers' perspective. Int. J. Proj. Manag. 2017, 35, 1084-1102. [CrossRef]

6. Banihashemi, S.; Hosseini, M.R.; Golizadeh, H.; Sankaran, S. Critical success factors (CSFs) for integration of sustainability into construction project management practices in developing countries. Int. J. Proj. Manag. 2017, 35, 1103-1119. [CrossRef]

7. Carvalho, M.; Junior, R.R. Impact of risk management on project performance: the importance of soft skills. Int. J. Prod. Res. 2014, 53, 321-340. [CrossRef]

8. Fernandez-Sanchez, G.; Rodríguez-López, F. A methodology to identify sustainability indicators in construction project management-Application to infrastructure projects in Spain. Ecol. Indic. 2010, 10, 1193-1201. [CrossRef]

9. Kivilä, J.; Martinsuo, M.; Vuorinen, L. Sustainable project management through project control in infrastructure projects. Int. J. Proj. Manag. 2017, 35, 1167-1183. [CrossRef]

10. A Sanchez, M. Integrating sustainability issues into project management. J. Clean. Prod. 2015, 96, 319-330. [CrossRef]

11. Hueskes, M.; Verhoest, K.; Block, T. Governing public-private partnerships for sustainability. Int. J. Proj. Manag. 2017, 35, 1184-1195. [CrossRef]

12. Marcelino, S.; González-Jaen, L.F.; Pérez-Ezcurdia, A. Using project management as a way to sustainability. From a comprehensive review to a framework definition. J. Clean. Prod. 2015, 99, 1-16. [CrossRef]

13. Khalifeh, A.; Farrell, P.; Al-Edenat, M. The impact of project sustainability management (PSM) on project success. J. Manag. Dev. 2019. [CrossRef] 
14. Sabini, L.; Muzio, D.; Alderman, N. 25 years of 'sustainable projects'. What we know and what the literature says. Int. J. Proj. Manag. 2019, 37, 820-838. [CrossRef]

15. Silvius, A.J.G. Sustainability as a new school of thought in project management. J. Clean. Prod. 2017, 166, 1479-1493. [CrossRef]

16. Økland, A. Gap Analysis for Incorporating Sustainability in Project Management. Procedia Comput. Sci. 2015, 64, 103-109. [CrossRef]

17. Silvius, A.J.G.; Schipper, R.P. Sustainability in project management: A literature review and impact analysis. Soc. Bus. 2014, 4, 63-96. [CrossRef]

18. Hope, A. Project management as if the world matters: At the intersection of sustainable development and project management. In Proceedings of the 12th Northumbria Research Conference, Newcastle upon Tyne, UK, 16-17 May 2012.

19. Moehler, R.; Hope, A.J.; Algeo, C. Sustainable Project Management: Revolution or Evolution? Acad. Manag. Proc. 2018, 2018, 13583.

20. Vos, R. Defining sustainability: a conceptual orientation. J. Chem. Technol. Biotechnol. 2007, 82, $334-339$. [CrossRef]

21. Huemann, M.; Silvius, G. Projects to create the future: Managing projects meets sustainable development. Int. J. Proj. Manag. 2017, 35, 1066-1070. [CrossRef]

22. Fuentes-Ardeo, L.; Otegi-Olaso, J.R.; Aguilar-Fernandez, M.E. How the project knowledge management and the sustainability in project management affect the project success. In Proceedings of the 2017 9th IEEE International Conference on Intelligent Data Acquisition and Advanced Computing Systems: Technology and Applications (IDAACS), Bucharest, Romania, 21-23 September 2017; Volume 2, pp. 884-887.

23. Carvalho, M.; Rabechini, R. Can project sustainability management impact project success? An empirical study applying a contingent approach. Int. J. Proj. Manag. 2017, 35, 1120-1132. [CrossRef]

24. Martens, M.L.; Carvalho, M. Sustainability and Success Variables in the Project Management Context: An Expert Panel. Proj. Manag. J. 2016, 47, 24-43. [CrossRef]

25. Silvius, A.J.G.; Schipper, R. Exploring the relationship between sustainability and project success—conceptual model and expected relationships. Int. J. Inf. Syst. Proj. Manag. 2016, 4, 5-22.

26. Martens, M.L.; De Carvalho, M.M.; Martens, C.D.P. Sustainability and success in project management: A forum with academic experts. In Proceedings of the IAMOT 2016-25th International Association for Management of Technology Conference, Proceedings: Technology—Future Thinking, Orlando, FL, USA, 15-19 May 2016; pp. 1347-1360.

27. Silvius, A.J.G.; Schipper, R. A Conceptual Model for Exploring the Relationship Between Sustainability and Project Success. Procedia Comput. Sci. 2015, 64, 334-342. [CrossRef]

28. Davis, K. Different stakeholder groups and their perceptions of project success. Int. J. Proj. Manag. 2014, 32, 189-201. [CrossRef]

29. Silvius, A.J.G.; Schipper, R.; Planko, J.; Brink, J.; van der Köhler, A. Sustainability in Project Management; Gower Publishing: Aldershot, UK, 2012.

30. Busscher, T.; Tillema, T.; Arts, J. In search of sustainable road infrastructure planning: How can we build on historical policy shifts? Transp. Policy 2015, 42, 42-51. [CrossRef]

31. Project Mangement Institute. Practice Standard for Project Risk Management; Project Mangement Institute: Newtown Square, PA, USA, 2009.

32. Brones, F.; Carvalho, M.; Zancul, E. Ecodesign in project management: a missing link for the integration of sustainability in product development? J. Clean. Prod. 2014, 80, 106-118. [CrossRef]

33. Beck, K.; Beedle, M.; van Bennekum, A.; Cockburn, A. Agile Manifesto. Available online: https://www. agilealliance.org/agile101/12-principles-behind-the-agile-manifesto/ (accessed on 12 February 2020).

34. Mirza, M.N.; Pourzolfaghar, Z.; Shahnazari, M. Significance of Scope in Project Success. Procedia Technol. 2013, 9, 722-729. [CrossRef]

35. Morris, P.W.G. Reconstructing Project Management; Wiley-Blackwell: Hoboken, NJ, USA, 2013.

36. Fageha, M.K.; Aibinu, A.A. Managing Project Scope Definition to Improve Stakeholders' Participation and Enhance Project Outcome. Procedia Soc. Behav. Sci. 2013, 74, 154-164. [CrossRef]

37. Asadabadi, M.R.; Chang, E.; Zwikael, O.; Saberi, M.; Sharpe, K. Hidden fuzzy information: Requirement specification and measurement of project provider performance using the best worst method. Fuzzy Sets Syst. 2020, 383, 127-145. [CrossRef] 
38. Femmer, H. Reviewing Natural Language Requirements with Requirements Smells-A Research Proposal, 11th International Doctoral Symposium on Empirical Software Engineering (IDoESE'13 at ESEM'13), Baltimore, Maryland USA, Research Gate 2013. Available online: https://www.researchgate.net/publication/281296224_Reviewing_Natural_Language_Requirements_ with_Requirements_Smells_-_A_Research_Proposal_- (accessed on 12 December 2019).

39. Locke, K. Grounded Theory in Management Research. Available online: https://methods.sagepub.com/ book/grounded-theory-in-management-researchhttps://methods.sagepub.com/book/grounded-theory-inmanagement-research (accessed on 11 June 2020).

40. Baxter, P.; Jack, S. Qualitative Case Study Methodology: Study Design and Implementation for Novice Researchers. Qual. Rep. 2008, 13, 544-559.

41. Verhaegen, P.-A.; Vandevenne, D.; Peeters, J.R.; Duflou, J. Refinements to the variety metric for idea evaluation. Des. Stud. 2013, 34, 243-263. [CrossRef]

42. A Guide to the Project Management Body Of Knowledge (PMBOK Guides); Project Management Institute, Four Campus Boulevard: Newtown Square, PA, USA, 2004; ISBN1 $193069945 X$. ISBN2 9781933890517.

43. Larson, E.W.; Gray, C.F. Project management: The managerial process; McGraw-Hill Irwin International Edition: New York, NY, USA, 2011.

44. Srinivasan, N.; Dhivya, S. An empirical study on stakeholder management in construction projects. Mater. Today Proc. 2020, 21, 60-62. [CrossRef]

45. Krane, H.P.; Rolstadås, A.; Olsson, N.O. A Case Study of How Stakeholder Management Influenced Project Uncertainty Regarding Project Benefits. Int. J. Inf. Technol. Proj. Manag. 2012, 3, 21-37. [CrossRef]

46. Eskerod, P.; Larsen, T. Advancing project stakeholder analysis by the concept 'shadows of the context'. Int. J. Proj. Manag. 2018, 36, 161-169. [CrossRef]

47. Martens, C.D.P.; Machado, F.J.; Martens, M.L.; Silva, F.Q.P.D.O.E.; De Freitas, H.M.R. Linking entrepreneurial orientation to project success. Int. J. Proj. Manag. 2018, 36, 255-266. [CrossRef]

48. De Wit, A. Measurement of project success. Int. J. Proj. Manag. 1988, 6, 164-170. [CrossRef]

49. Söderlund, J. Reinventing Project Management: The Diamond Approach to Successful Growth and Innovation. By Aaron J. Shenhar and Dov Dvir. RED Manag. 2008, 38, 355-356. [CrossRef]

50. Kerzner, H. Project Management: A Systems Approach to Planning, Scheduling, and Controlling; John Wiley \& Sons, Inc.: New York, NY, USA, 2005; ISBN 0471741876.

51. Sustainability Integration for Effective Project Management. Available online: https://www.researchgate. net/publication/291743973_Sustainability_integration_for_effective_project_management (accessed on 11 June 2020).

52. Shuaib, M.; Seevers, D.; Zhang, X.; Badurdeen, F.; Rouch, K.E.; Jawahir, I. Product Sustainability Index (ProdSI). J. Ind. Ecol. 2014, 18, 491-507. [CrossRef]

53. Uribe, D.; Ortiz-Marcos, I.; Uruburu, Á. What Is Going on with Stakeholder Theory in Project Management Literature? A Symbiotic Relationship for Sustainability. Sustainability 2018, 10, 1300. [CrossRef]

54. Lee, M.T.; Raschke, R. Innovative sustainability and stakeholders' shared understanding: The secret sauce to "performance with a purpose". J. Bus. Res. 2020, 108, 20-28. [CrossRef]

55. Romestant, F. Sustainability agencing: The involvement of stakeholder networks in megaprojects. Ind. Mark. Manag. 2019. [CrossRef]

56. Hai, A.T.N.; Speelman, S. Involving stakeholders to support sustainable development of the marine lobster aquaculture sector in Vietnam. Mar. Policy 2020, 113, 103799. [CrossRef]

57. Bahadorestani, A.; Naderpajouh, N.; Sadiq, R. Planning for sustainable stakeholder engagement based on the assessment of conflicting interests in projects. J. Clean. Prod. 2020, 242, 118402. [CrossRef]

58. Ghassim, B.; Bogers, M. Linking stakeholder engagement to profitability through sustainability-oriented innovation: A quantitative study of the minerals industry. J. Clean. Prod. 2019, 224, 905-919. [CrossRef]

59. Amaya, J.; Arellana, J.; Delgado-Lindeman, M. Stakeholders perceptions to sustainable urban freight policies in emerging markets. Transp. Res. Part A: Policy Pr. 2020, 132, 329-348. [CrossRef]

60. Danso, A.; Adomako, S.; Lartey, T.A.; Amankwah-Amoah, J.; Owusu-Yirenkyi, D. Stakeholder integration, environmental sustainability orientation and financial performance. J. Bus. Res. 2019. [CrossRef]

61. Dharmayat, K.I.; Tran, T.; Hardy, V.; Chirambo, B.G.; Thompson, M.J.; Ide, N.; Carlsson, S.; Andersson, B.; O'donoghue, J.M.; Mastellos, N.; et al. Understanding stakeholders' approaches to sustainability in building projects. Sustain. Integr. Eff. Proj. Manag. 2014, 12, 188-197. 
62. Gibson, J.G.E.; Wang, Y.-R.; Cho, C.-S.; Pappas, M.P. What Is Preproject Planning, Anyway? J. Manag. Eng. 2006, 22, 35-42. [CrossRef]

63. Atkinson, R.; Crawford, L.; Ward, S. Fundamental uncertainties in projects and the scope of project management. Int. J. Proj. Manag. 2006, 24, 687-698. [CrossRef]

64. Ooi, S.M.; Lim, R.; Lim, C.C. An integrated system for end-to-end traceability and requirements test coverage. In Proceedings of the 2014 IEEE 5th International Conference on Software Engineering and Service Science, Beijing, China, 27-29 June 2014; pp. 45-48.

65. Dalpiaz, F.; Van Der Schalk, I.; Lucassen, G. Pinpointing Ambiguity and Incompleteness in Requirements Engineering via Information Visualization and NLP. Lect. Notes Comput. Sci. 2018, 119-135. [CrossRef]

66. Rossanez, A.; Carvalho, A.M. Semi-Automatic Checklist Quality Assessment of Natural Language Requirements for Space Applications. In Proceedings of the 2016 Seventh Latin-American Symposium on Dependable Computing (LADC), Cali, Colombia, 19-21 October 2016; pp. 123-126. [CrossRef]

67. Kof, L. Treatment of Passive Voice and Conjunctions in Use Case Documents. Intelligent Tutoring Systems 2007, 4592, 181-192.

68. Mallek, S.; Daclin, N.; Chapurlat, V.; Vallespir, B. Requirements Formalization for Systems Engineering: An Approach for Interoperability Analysis in Collaborative Process Model. Enterp. Interoperability 2014, 243-257.

69. Femmer, H.; Fernández, D.M.; Wagner, S.; Eder, S. Rapid quality assurance with Requirements Smells. J. Syst. Softw. 2017, 123, 190-213. [CrossRef]

70. Yen, J.; Lee, J. Fuzzy logic as a basis for specifying imprecise requirements. In Proceedings of the [Proceedings 1993] Second IEEE International Conference on Fuzzy Systems, San Francisco, CA, USA, 28 March-1 April 1993; pp. 745-749.

71. Krogstie, J.; Lindland, O.I.; Sindre, G. Towards a deeper understanding of quality in requirements engineering. Notes Numer. Fluid Mech. Multidiscip. Des. 1995, 932, 82-95.

72. Gibson, G.; Podesta, T.; Carlsson, E.; Mitrocsak, R. Project Definition Rating Index, Infrastructure Projects; Implementation Resource 268-2; Construction Industry Institute, The University of Texas at Austin: Austin, TX, USA, 2010.

73. Liu, X. Fuzzy requirements. IEEE Potentials 1998, 17, 24-26. [CrossRef]

74. Shojaei, P.; Haeri, S.A.S. Development of supply chain risk management approaches for construction projects: A grounded theory approach. Comput. Ind. Eng. 2019, 128, 837-850. [CrossRef]

75. Glaser, B.; Strauss, A. The Discovery of Grounded Theory; Weidenf. Nicolson: London, UK, 1967.

76. Hollweck, T. Robert K. Yin. (2014). Case Study Research Design and Methods (5th ed.). Thousand Oaks, CA: Sage. 282 pages. Can. J. Program Eval. 2016, 282. [CrossRef]

77. Keeys, L.A.; Huemann, M. Project benefits co-creation: Shaping sustainable development benefits. Int. J. Proj. Manag. 2017, 35, 1196-1212. [CrossRef]

78. Zadeh, L. Fuzzy sets. Inf. Control. 1965, 8, 338-353. [CrossRef]

(C) 2020 by the authors. Licensee MDPI, Basel, Switzerland. This article is an open access article distributed under the terms and conditions of the Creative Commons Attribution (CC BY) license (http://creativecommons.org/licenses/by/4.0/). 